3. Santos-Briz A Jr, Serrano R, del Cañizo A et al. Liesegang rings in a dermoid cyst of the floor of the mouth. Acta Cytol. 2000; 6; 1062 1065.

4. Koss LG. Diagnostic cytology of the urinary tract. Philadelphia: Lippincott-Raven, 1996.

\section{CD1a immunopositivity could help to address prognosis of intestinal-type Barrett's metaplasia}

Sir: I read with great interest the letter of Lopes et al. that compared Alcian blue-periodic acid-Schiff stain with immunohistochemistry for MUC-2 in 40 patients with Barrett's metaplasia (BM) of intestinal-type (IT). ${ }^{1}$ In their research, they found that 'MUC-2 expression turned out to be a helpful tool for the correct identification of intestinal metaplasia, avoiding any false-negative of even false-positive results'.

We agree with them that 'an adequate diagnosis' of $\mathrm{BM}$ 'is very important' for the management of this disease, but since 'the incidence of adenocarcinoma in this epithelium ranges between $0.2 \%$ and $2.1 \%$ in patients without dysplasia and up to $70 \%$ in those with high-grade dysplasia', we consider of greater interest to have a test that may help to predict the prognosis.

As the anti-tumoral role of CD1a was recently postulated, we investigated its presence in metaplastic epithelium of Barrett's oesophagus, both gastric and IT. $\mathrm{CD} 1 \mathrm{a}$ is a surface glycoprotein of $49 \mathrm{kDa}$ commonly expressed by dendritic cells, cortical thymocytes and Langerhans cells of skin and mucosa; moreover, immunoexpression of $\mathrm{CD1a}$ is commonly researched to differentiate various cutaneous lymphomas (T-cell) from B-cell lymphomas and pseudolymphomas.

In a preliminary work on 113 biopsies of BM, we reported that the most of cases $(75 \%)$ of $\mathrm{BM}$ were positive for $\mathrm{CD} 1 \mathrm{a} ;{ }^{2}$ in particular, we were the first to demonstrate that $\mathrm{CD} 1 \mathrm{a}$ could be expressed by epithelial cells, other that dendritic cells, in BM. Consequently, we reported that the expression of $\mathrm{CD} 1 \mathrm{a}$ by metaplastic epithelial cells might help to distinguish BM by the presence of heterotopic mucosa in the esophageal wall.

Recently, we examined 65 patients with IT BM and we found that 55 of them were positive for CDla (Figure 1A), while normal intestinal mucosa is always negative (Figure 1B). Nevertheless, eight of 10 patients that were negative for $\mathrm{CD} 1 \mathrm{a}$ underwent dysplasia at 1-3 years follow-up. Dysplastic tissues were also negative for $\mathrm{CD} 1 \mathrm{a}$ (Figure 1C). By contrast, IT BM diagnosis was confirmed at follow-up of all 55 positive cases.

Our data already suggested that this marker might help to predict the prognosis of this pathology in both
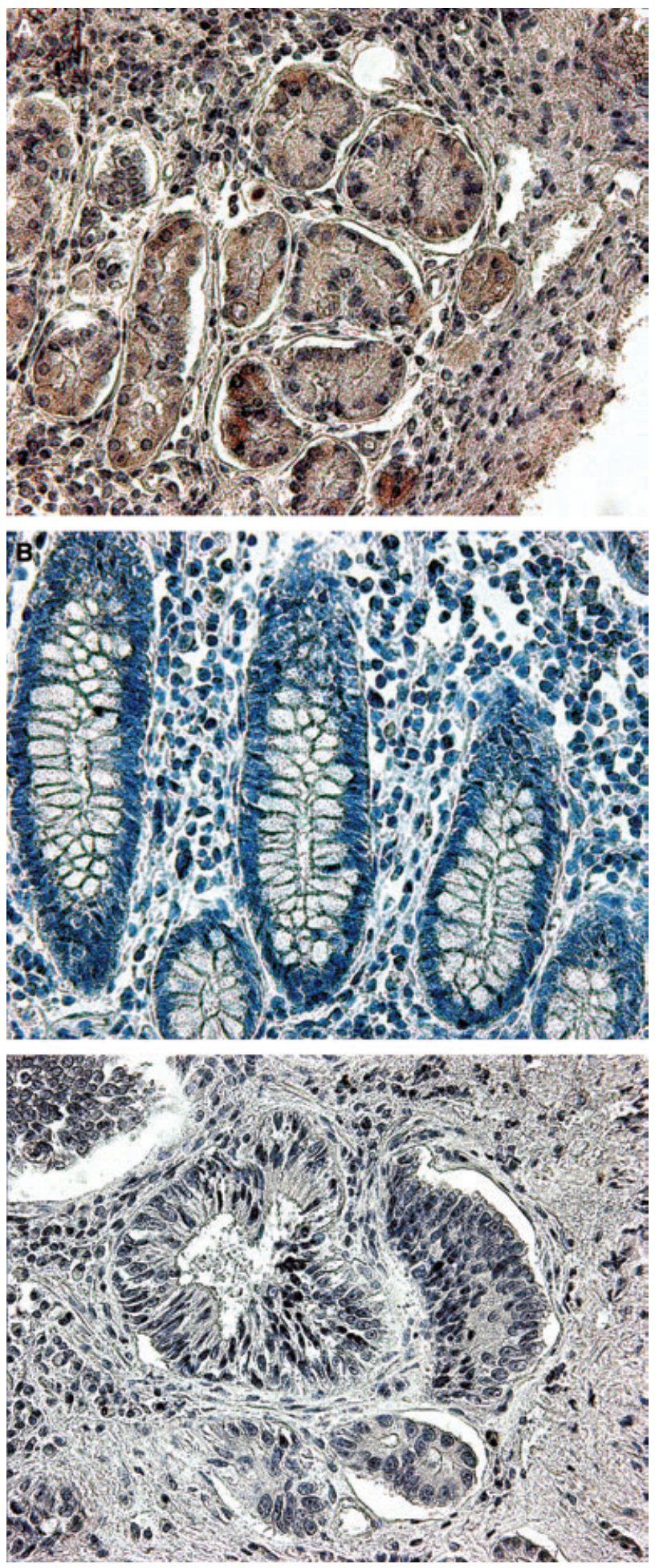

Figure 1. A, Immunohistochemistry for CD1a in IT BM shows this marker localized above all in epithelial cells. B, Normal intestinal mucosa does not express this protein. C, Dysplasia on IT BM does not show any immunopositivity. 
gastric- and IT BM. ${ }^{2}$ In light of our recent experiments, we feel it necessary to confirm this hypothesis.

In conclusion, although malignant transformation may be a rare event, we suggest that $\mathrm{CD} 1$ a could be a new marker not only to distinguish heterotopic mucosa from BM but also to predict the prognosis of this condition.

\section{F Cappello G Zummo}

Department of Experimental Medicine, University of Palermo, Palermo, Italy

1. Lopes CV, Pereira-Lima JC, Hartmann AA. Correlation between Alcian blue-periodic acid-Schiff stain and immunohistochemical expression of mucin 2 in Barrett's oesophagus. Histopathology 2004; 45; 198.

2. Cappello F, Rappa F, Bucchieri F, Zummo G. CD1a: a novel biomarker for Barrett's metaplasia?. Lancet Oncol. 2003; 4; 497.
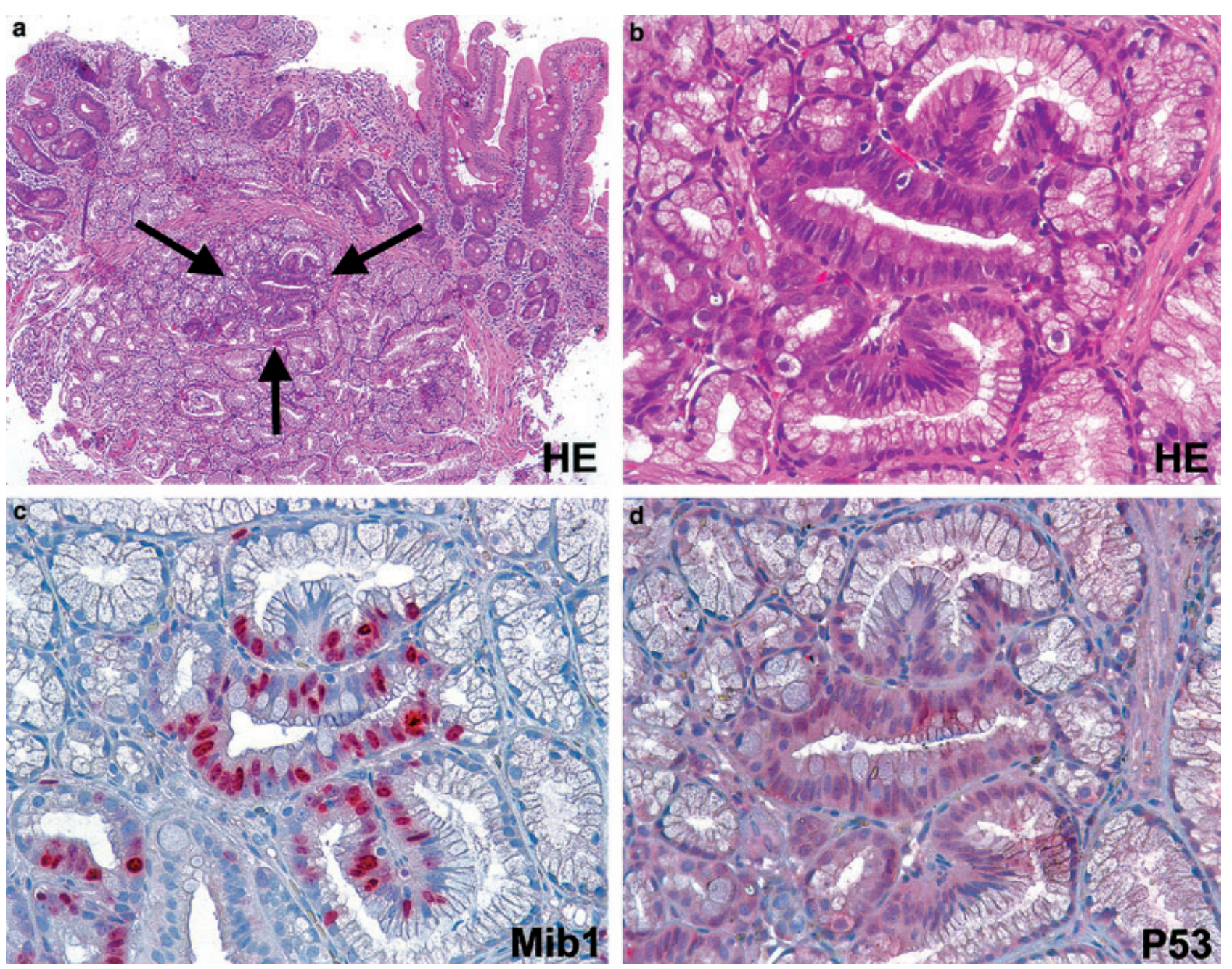

Figure 1. Small focus of low-grade intraepithelial neoplasia of Brunner's gland in conventional histology (a and b) and immunohistochemistry with antibodies against MIB-1 (c) and p53 (d).
Sir: Most Brunner's gland tumours within the duodenum, so called Brunner's gland adenomas or brunneriomas, are not true neoplasms but represent hyperplasias or hamartomas consisting of mature mucus-producing glands. ${ }^{1}$ We would like to report the very rare case of low-grade intraepithelial neoplasia of Brunner's gland.

A 69-year-old woman underwent esophago-gastroduodenoscpy because of suspected esophageal varices. In the duodenum multiple small elevations of the duodenal mucosa were found and duodenal biopsies were taken.

Histological examination of the duodenal biopsies revealed lobulated and hyperplastic Brunner's glands (Figure 1a) with a small focus of apparently neoplastic 